\title{
How can neuroscience contribute to moral philosophy, psychology and education based on Aristotelian virtue ethics?
}

\author{
Hyemin $\operatorname{Han}^{1}$
}

Published online: 24 February 2016

C) Springer International Publishing AG 2016

\begin{abstract}
The present essay discusses the relationship between moral philosophy, psychology and education based on virtue ethics, contemporary neuroscience, and how neuroscientific methods can contribute to studies of moral virtue and character. First, the present essay considers whether the mechanism of moral motivation and developmental model of virtue and character are well supported by neuroscientific evidence. Particularly, it examines whether the evidence provided by neuroscientific studies can support the core argument of virtue ethics, that is, motivational externalism. Second, it discusses how experimental methods of neuroscience can be applied to studies in human morality. Particularly, the present essay examines how functional and structural neuroimaging methods can contribute to the development of the fields by reviewing the findings of recent social and developmental neuroimaging experiments. Meanwhile, the present essay also considers some limitations embedded in such discussions regarding the relationship between the fields and suggests directions for future studies to address these limitations.
\end{abstract}

Keywords Virtue ethics · Moral philosophy · Moral education · Moral development . Neuroscience

\section{Introduction}

Moral philosophers and psychologists have proposed diverse perspectives to deal with the debates regarding the definition of morality. First, we may consider outcomeoriented or rule-based moral philosophical viewpoints (Barnett et al. 2005). Basically, these standpoints are mainly interested behavioural outcomes (consequentialism) or

Hyemin Han

gksgpals@stanford.edu

1 Stanford Graduate School of Education, 485 Lasuen Mall, Stanford, CA 94305-3096, USA 
moral rules (deontology) instead of an actor's disposition or character while making moral judgment (Sinnott-Armstrong 2011; Alexander and Moore 2012). Consequently, moral psychological models based on this philosophical vantage point, such as the Kohlbergian model, which employs ideas of Kantian, Rawlsian and utilitarian moral philosophy (Kohlberg 1981; Blum 1988) to establish its philosophical framework, tend to emphasize the role of moral cognition and moral reasoning that are essential in evaluating norms, rules and predicted behavioural outcomes in moral judgment. According to this viewpoint, moral behaviour or motivation is defined as a behaviour or motivation originated from the obedience to moral principle (in case of deontology) or that maximizes goods (in case of consequentialism) (Nunner-Winkler 1997; De Colle and Werhane 2008). On the other hand, the proponents of virtue ethics have proposed significant counterarguments against the outcome-oriented or rule-based viewpoints (Hursthouse 2012). Unlike previously mentioned viewpoints, those proponents argue that happiness or flourishing (eudaimonia) of a person is most fundamental in morality (Snow 2008; Kraut 2014). They contend that moral virtue, which becomes the basis of morality, can be regarded as a long-term, habituated and internalized disposition that eventually leads us to eudaimonia with the guidance of practical wisdom (phronesis) (Curzer 2012; Silverstein and Trombetti 2013; Kristjánsson 2014). Phronesis, or practical wisdom, is defined as reasoning enabling us to make an appropriate decision in a certain situation, which leads us to the middle way (Sanderse 2012). A developmental and psychological model based on this philosophical vantage point argues that the process of early habituation and later cultivation of phronesis are fundamentally required (Kristjánsson 2007a; Carr 2008; Han 2015); it particularly underscores the development of integrative moral character (Arthur 2003; Hartman 2006) enabling us to make an appropriate moral decision and to adjust our emotional and motivational forces at an appropriate level guided by phronesis (Kristjánsson 2000; Molewijk et al. 2011), rather than the development of a specific moral function, such as moral reasoning in the case of Kohlbergian theory.

Based on these aspects of virtue ethics and virtue ethical moral psychology and education, the present study will delve into the relationship between virtue ethics and neuroscience. First, the present essay, which is interested in moral education as well as moral philosophy, surmises that the theoretical framework of virtue moral philosophy seems to be more coherent with the recent integrative moral educational approach that aims to foster students' moral character, which embraces all aspects of human moralityi.e., moral reasoning, moral affection and moral behaviour (Lickona 1996; Berkowitz 2002; Blasi 2005; Narvaez and Lapsley 2005; Althof and Berkowitz 2006) — comparing to other moral philosophical viewpoints. Moral psychological models originating from outcome-oriented or rule-based moral philosophy tend to focus on the development of certain aspects of moral functioning, particularly moral reasoning in the case of Kohlbergian moral psychology (Kohlberg 1981, 1984), so they are not likely to be suitable for directly applying to moral education aiming at developing holistic moral character. Instead, a more inclusive theoretical framework, virtue ethics, equally underscores the role of moral habit, disposition and phronesis (Kristjánsson 2013; Kraut 2014). Second, its developmental model (Sanderse 2014) would provide more useful insights to scholars and educators. Finally, the naturalistic aspect of Aristotelian virtue ethics would make it be better supported by scientific evidence comparing to other moral philosophical perspectives (Kristjánsson 2007a; Jeong and Han 2013; Jacobs 2014). Therefore, the 
present essay will concentrate on virtue ethics and its psychological and educational models among diverse theoretical frameworks while exploring the connection between recent neuroscience and studies of human morality.

Neuroscientists have sought the neural substrate of human morality, which establishes biological basis of moral behaviour, using various methods, such as functional and structural neuroimaging and non-invasive brain stimulation methods (Poldrack 2008; Young et al. 2010; Tassy et al. 2012; Jeurissen et al. 2014). They have demonstrated how activity in brain regions associated with affection, cognition, motivation and other moral psychological processes are related to moral functioning. These neuroscientific studies of human morality have significantly and pervasively influenced other traditional disciplines dealing with morality including, but not limited to, moral philosophy, moral psychology and moral education (Narvaez and Vaydich 2008; Han 2014). For instance, previous neuroimaging studies investigating the involvement of affective processes in moral cognition proposed a novel idea about moral psychological mechanisms of deontological and utilitarian moral decision-making, which provided a new vantage point to moral philosophy (Greene et al. 2001, 2004; Greene 2007).

The present essay will start with discussing how the recent neuroscience can support moral philosophical and psychological accounts of human morality proposed by virtue theorists by reviewing empirical evidence. In the first section, the present essay will focus on whether the moral philosophical basis of Aristotelian virtue ethics is coherent with neuroscientific evidence and how well the evidence can explain its psychological and developmental models. Furthermore, the second section will consider the future directions of neuroimaging studies focusing on moral virtue and character. More specifically, this essay will concentrate on how neuroimaging methods can contribute to the scientific investigation of virtue, character development, and finally, the development of educational methods based on this viewpoint.

\section{Exploring the relationship between Aristotelian virtue theory and neuroscience}

This section consists of two sub-sections dealing with the core philosophical basis (first part) and developmental processes (second part) proposed by Aristotelian ethics. First, I discuss whether the core philosophical element of Aristotelian moral philosophy, that is, motivational externalism (Kristjánsson 2012), which argues the necessity of emotional and motivational elements, which are independent from moral reasoning for moral action (Zagzebski 1996), can be supported by neuroscientific evidence. Second, I discuss whether findings in developmental neuroscience correspond to the model of amoral developmental theory proposed by Aristotelian ethics, which especially underscores the habituation of virtue as well as the cultivation phronesis (Hursthouse 2012; Kristjánsson 2014).

\section{Motivational externalism and social neuroscience}

There have been continuous controversies regarding the relationship between moral reasoning and moral behaviour. More specifically, scholars have debated whether moral decision based on moral reasoning does necessarily result in actual behaviour. There 
are two distinctive points of view explaining the relationship: motivational internalism and motivational externalism. The proponents of motivational internalism, motivational internalists, argue that moral judgment itself generates motivation for behaviour (Rosati 2006). On the other hand, motivational externalists proposing motivational externalism contend that moral judgment does not necessarily generate moral behavioural outcome; instead, they argue that other motivational factors, such as a strong will, are required to bridge the gap between judgment and behaviour (Rosati 2006).

In this section, the present essay will discuss why motivational externalism seems to be more convincing and better explain the reality compared to motivational internalism based on empirical evidence in the fields of psychology and neuroscience. Of course, motivational internalism perhaps is perhaps better than motivational externalism in terms of its structure. Motivational internalism explains the mechanism of moral behaviour with a relatively simple and straightforward model (Mele 1989; ShaferLandau 2000; Bjorklund et al. 2012); it does not require the complicated involvement of diverse psychological constructs or components, such as a will, to explain how motivation is generated. Also, as shown by the Kohlbergian model of moral reasoning development (Kohlberg 1981, 1984), the internalism model was perhaps supported by empirical evidence. However, since the foundation of internalism is being threatened by the recent findings from psychological and neuroscientific studies, the present essay will discuss why externalism is a more plausible framework explaining the mechanism of moral behaviour.

Social neuroscience suggests that motivation for moral behaviour does not originate directly from the result of moral judgment, as argued by motivational internalists. Instead, it implies that other psychological processes, particularly affective and rewarding processes, are inevitably involved in the formation of moral motivation and action, as proposed by motivational externalists. Motivational internalism argues, "a person cannot sincerely make a moral judgment without being motivated at least to some degree to abide by her judgment" (Rosati 2006). Although there are two types of internalism, strong and weak, both acknowledge that moral judgment is necessary in moral motivation and action (Rosati 2006). Several neuroscientific experiments are not consistent with those standpoints.

First, brain lesion studies focusing on human morality significantly threaten the validity of strong internalism. The case study of Phineas Gage demonstrated that the lesion in the prefrontal cortex caused significant deficiency in socio-moral adjustment (Barker 1995). Although his intellectual ability to make judgments was intact for a while, his socio-moral character and behavioural tendency were severely regressed immediately after the accident (Kihlstrom 2010). Moreover, a recent experiment investigated more directly the association between the lesion in the medial prefrontal cortex, which deals with affection, and the integration of motivational force (Tranel 2002), moral reasoning, and moral motivation (Saver and Damasio 1991). This experiment demonstrated that, for patients whose medial prefrontal cortex was damaged during their adulthood, although their average moral judgment score was not significantly worse than that of normal participants, they showed severe socio-moral maladjustment, embodied by a morally inappropriate behavioural tendency. Given these experiments, strong motivational internalism can be refuted, because although those presented patients were able to make sound moral judgments and their moral reasoning was intact, their moral motivation and behavioural tendency were significantly 
deficient. Thus, moral judgment cannot be a sufficient condition for moral motivation and behaviour.

Second, the validity of weak internalism can also be criticized by neuroscientific evidence. Although weak internalism endorses that mental illness or another motivational force can override the result of sound moral judgment, it still maintains the position that sound moral judgment is at least a necessary condition for moral motivation and behaviour (Brink 1997). Thus, counterexamples, demonstrating that moral motivation and behaviour can be generated without moral judgment, can threaten this version of internalism. In fact, behavioural and developmental neurosciences focusing on moral motivation and behaviour in infancy show us the possibility of moral motivation and behaviour without sophisticated formal moral judgment (Decety and Howard 2013). For instance, even very young infants, such as 3-months-olds (Hamlin et al. 2010) or 6-months-olds (Hamlin et al. 2007), are motivated to prefer prosocial and moral behaviour over antisocial and anti-moral behaviour, although they are not capable of making sound and sophisticated moral judgments (Piaget 1948; Kohlberg 1984). Scholars suggest that this phenomenon occurs due to the presence of hard-wired morality in infants' brains (Bloom 2012). Because Aristotelian virtue ethics acknowledges that children can have rudimentary forms of moral virtues, although those virtues are not full virtues moderated by phronesis (Kraut 2014), the results of these scientific experiments may indicate that moral motivation and behaviour, at least in their rudimentary forms, can exist even among infants. Hence, those counterexamples can threaten the validity of weak motivational internalism, and support the core of Aristotelian ethics, that is, motivational externalism.

However, some may contend that we should consider other components on top of explicit behavioural outcome itself while we are evaluating the moral aspect of behaviour. For instance, although Phineas Gage's behaviour was socially inappropriate and can be considered to be anti-moral, his behaviour may not be completely anti-moral because he may not possess a mental ability to take moral responsibility due to the brain injury; if he lacked such a mental ability, we cannot blame him for behaving antimorally (Fischer and Ravizza 2000). Moreover, children's prosocial behavioural tendency presented in psychological studies may also not be regarded as moral behavioural tendency. Since moral philosophers have argued that we should evaluate the moral aspect of certain behaviour based on not only its behavioural outcome itself but also its intention (Anscome 1958; Pellegrino 1995), it would be inappropriate to say that children's prosocial behaviour initially generated by instinct is moral. Thus, we should consider these factors, i.e., responsibility and intention, while evaluating certain behaviour.

Then, how the components of responsibility and intention in moral behaviour is related to the prior discussion of the validity of motivational externalism? The present study intends to review previous psychological studies examining the psychological mechanism and neural correlates of moral responsibility and intention. Previous social psychological works have shown that people may withdraw themselves from moral behaviour even when they made a sound moral judgment due to moral disengagement originating from the lack of the sense of responsibility (Bandura 1990, 1999). Also, previous neuroimaging studies have demonstrated that a brain circuitry associated with self-agency and possibility the sense of responsibility was significantly activated in moral decision-making task conditions (Moll et al. 2007), and it significantly interacted 
with brain regions associated with moral judgment (Han et al. 2016). Furthermore, a recent experiment demonstrated that the factor of intention influenced behavioural outcome on top of decision-making processes (Greene et al. 2009); a neuroimaging study also found the neural correlates of intention judgment by setting the type of intention as an independent variable (Borg et al. 2006). Given these previous studies, the present essay shall conclude that the psychological and neural mechanism of responsibility and intention are perhaps independent from those of moral reasoning itself in the generation of behavioural motivation, and they would empirically support motivational externalism, not motivational internalism.

\section{Development of moral virtue and developmental neuroscience}

Findings in developmental neuroscience also support the developmental model of Aristotelian ethicists. Both early habituation and internalization of moral virtue, as well as cultivation of phronesis, which moderates motivational forces to be appropriately exerted in a given situation, are necessary for the achievement of the ultimate purpose of human life, that is, eudaimonia (Aristotle 2000; Wall 2003; Kristjánsson 2014), according to Aristotelian perspective.

First, the previous lesion study demonstrated that the average moral judgment interview score among patients with early-onset prefrontal damage was significantly worse than that of normal participants. This study proposed that patients with such damage were not able to internalize moral norms into their brain reward system, hindering their further development of moral reasoning, given the somatic marker hypothesis (Saver and Damasio 1991; Damasio 1994). It can support the standpoint of Aristotelian moral development, which emphasizes the importance of early habituation of moral norms for the acquisition of moral virtue and eudaimonia. Of course, a continent person, who has developed moral reasoning without early-habituation of moral virtue, can behave morally because she knows well what is morally appropriate (Kristjánsson 2013; Fowers 2014); however, because moral norm and affection are not completely integrated into her selfhood, they become a sort of external imperative for her, not a natural trait, and can hardly serve for her moral flourishing and happiness (Stocker 2003). Thus, the neuroscientific investigation corresponds to this Aristotelian account on moral development, which emphasizes the importance of early internalization of moral virtue for the future development of moral character, including moral reasoning.

Second, developmental brain studies have shown that the Aristotelian version of the moral developmental course, which consists of the habituation of norms and cultivation of wisdom, may occur in the physical reality. According to this idea, the early habituation and internalization of moral norms through repetitive behavioural training, followed by the cultivation of phronesis, are required for the development of moral character (Carr 2008; Kristjánsson 2014). Some neuroimaging studies have demonstrated that one of the most salient aspects of moral development at the neural level during early-childhood through early-adolescence is that brain regions associated with the motivational and reward system (e.g., amygdala, nucleus accumbens, orbitofrontal cortex, ventral striatum), which engages in the habituation and internalization of rules (Wilson and Rolls 2005; Blair 2007), develop earlier than regions associated with 
sophisticated reasoning (Galvan et al. 2006; Hare et al. 2008; Decety et al. 2012). This aspect would also be supported by neuroimaging studies demonstrating that habituation actually influences the neural mechanism of affection and motivation (Tricomi et al. 2009; Lingawi and Balleine 2012; de Wit et al. 2012). Then, in regions correlated with reasoning based on prudence, self-control, and sophisticated self-reflective processes (e.g., lateral prefrontal cortex, posterior cingulate cortex) (Moll et al. 2007; Buckner et al. 2008; Immordino-Yang et al. 2012), that correspond to the concept of phronesis in Aristotelian philosophy, the activity becomes salient beyond adolescence (Casey et al. 2008; Wright et al. 2008; Harenski et al. 2012). This neural-level developmental trend suggests that the moral developmental course proposed by Aristotelian ethics may actually occur in the human brain.

Although there have been no neuroscientific studies that directly focused on the neural-level effect of moral educational interventions, some experiments can shed light on this issue. First, training programs designed for the habituation of certain actions, such as juggling, induced myelination in regions associated with the function (Scholz et al. 2009). Second, even for the cultivation of reasoning, which is more sophisticated than the case of habituation, interventions, such as board games (Lee et al. 2010), reasoning exercises (Mackey et al. 2012), working memory training (Olesen et al. 2004; Takeuchi et al. 2010), and meditation programs (Lazar et al. 2005), promoted significant structural changes in brain regions associated with cognition and reasoning. These results would support the idea that Aristotelian ways for moral education-i.e., habituation and phronesis cultivation - actually influences the brain structure according to the idea of neuroplasticity (LeDoux 2002) and previous neuroscientific studies demonstrating the neural-level effect of habituation and learning (Tricomi et al. 2009; Lingawi and Balleine 2012; de Wit et al. 2012).

\section{Utilizing neuroscientific methods to investigate moral development}

Moral virtue has been an important issue in the fields of moral psychology and education. Moral psychologists and educators who aim to develop students' character as a whole tend to pay their attention to the concept of integrative moral virtue rather than individual moral function, such as moral cognition or affection (C. Lee and Taylor 2013). To accurately diagnose the current developmental status and evaluate the effects of educational endeavours, scholars need a well-developed measurement of moral virtue. Then what are possible ways to measure the development of moral virtue? It seems to be difficult to properly measure this conceptual construct because we, human, cannot have a perfect insight into a subjects' mind with scientific methods; we can only have proxies to the mind, instead of "mind reading strategies," to conduct a scientific investigation of moral virtue. Aristotle gave us a hint about one possible proxy of moral virtue.

If a man once acquires reason, that makes a difference in action; and his state, while still like what it was, will then be virtue in the strict sense. (Aristotle 2000)

Behavioural observation would be a possible way to assess whether a person possesses a certain moral virtue in his/her self, given the quote of Aristotle. In fact, 
this method has been frequently utilized by developmental psychologists, particularly who are interested in early childhood development (Woodhead and Paulkner 2000). However, there are significant limitations in this method. First, a mere presence of moral behaviour cannot prove that the actor of the behaviour possesses moral virtue. According to Aristotle's account on the habituation of moral virtue and moral character, the repetition and consistency of the moral behaviour are more important than a mere presence of the behaviour (Aristotle 2000). Thus, the observation of moral behaviour in an empirical study, which is usually conducted during a short period, does not necessarily confirm that a participant has completely integrated moral virtue into his/ her self. In addition, we should be aware of the possibility of social and desirability biases. Participants do not behave as they actually behave in their everyday lives because they want to show that they behave in a moral and socially desirable manner to observers (Adair 1984). Because of these reasons, thus, the reliability and credibility of behavioural observation to measure moral virtue would be severely threatened.

These limitations are also common to the questionnaire method, which is usually being utilized by moral psychologists and educators (Kristjánsson 2013). The desirability bias is also an important issue in this case. For instance, if we ask our participants to rate the importance of keywords, which include both moral and nonmoral ones, to them, they would naturally tend to rate moral keywords are important to them regardless of whether the moral values and virtues embedded in the keywords are really important to them, and integrated into their selfhood because they want to show that they are moral people. In addition, validity would not also be guaranteed; in other words, we are not sure about whether we can measure moral virtue, which is inevitably internal and covert, with a paper-and-pencil questionnaire.

Therefore, moral philosophers and psychologists need a more direct approach to internal psychological processes that enables them to properly measure the development of moral virtue. Neuroimaging methods, which have been rapidly developed during last couple of decades, would address the problems of previous methods. The neuroimaging methods present significant advantages over current methods for assessing moral development such as self-reporting, which (1) do not give scientists insight into the substructures that process moral virtue and that underlie manifest behaviour; and which (2) are biased by respondents' subjectivity (Ito and Cacioppo 2007).

\section{Neuroimaging methods to measure moral virtue}

The neuroscientific investigations of moral virtue can start by examining moral exemplars who are realizing moral virtue in their lives. Colby and Damon (1992) emphasized that empirical studies of moral exemplars can provide us with useful insights regarding the nature of human morality, which could not be completely examined by traditional moral psychological studies targeted at ordinary people. Because the moral exemplars are a paragon of moral virtue, it would be informative to investigate their developmental and psychological characteristics. In fact, this "reverse-engineering method" shows us how moral virtue works in reality through the real exemplars (Walker 2013). Thus, comparing brains between moral exemplars that have already acquired moral virtue and ordinary people is a good starting point of our endeavours to measure the internal mechanism of moral virtue. 
Functional neuroimaging Given the theoretical framework of virtue ethics and character psychology, the integration of moral virtue into a person's selfhood is an important goal in character development (Kristjánsson 2007b). Thus, it is reasonable to research the link between moral virtue to an individual's sense of "self" to examine the development of moral virtue. At the neural level, this research can be conducted by measuring the connectivity between brain regions associated with moral virtue and selfrelated processes, such as self-reflection and self-referencing (Buckner et al. 2008).

The neuroimaging studies of the default mode network (DMN), which is closely associated with psychological processes regarding the selfhood, self-referential and autobiographic processes (Immordino-Yang et al. 2012) are particularly informative for our research on the mechanisms of selfhood and self-related psychological processes at the neural level. In these DMN studies, scientists have reported that certain brain regions were deactivated while participants were consciously involved in cognitive tasks. On the contrary, these regions were activated when the participants were in resting state. This pattern significantly differed from the pattern usually reported in previous neuroimaging studies. The regions included the medial prefrontal cortex (MPFC), posterior cingulate cortex (PCC), precuneus, and inferior parietal lobule (IPL). The scientists named the network of these regions, which has only been activated during resting state, as the DMN; and they hypothesized that this network would be related to introspective self-related psychological processes, instead of goal-driven cognitive functions (Buckner et al. 2008).

As the scientists hypothesized, an interesting aspect of the DMN is that this network is extensively activated when participants are requested to do a sort of self-related tasks. For instance, the DMN was significantly more activated during the self-adjective association ask condition than other-adjective task association condition (Zhu et al. 2007). In addition, when a part of this network, the precuneus, was disrupted by the transcraniel magnetic stimulation (TMS), the efficiency of the self-adjective association task declined and became identical to that of the other-adjective association task (Lou et al. 2010). Thus, given these findings, the DMN is the neural network extensively associated with the selfhood and its related psychological processes.

In fact, recent neuroimaging studies that examined the neural substrate of admiration showed that the PCC and precuneus in the DMN were particularly activated under the moral virtue admiration condition compared with the physical excellence admiration condition (Immordino-Yang et al. 2009; Englander et al. 2012). In addition, previous functional neuroimaging studies have consistently demonstrated that the ventromedial prefrontal cortex (VMPFC) and orbitofrontal cortex (OFC), which constitute the DMN, were significantly associated with prosocial and moral emotion and moral cognition (Moll et al. 2007; Moll and de Oliveira-Souza 2007; Reniers et al. 2012; Han et al. 2014, 2016; Sevinc and Spreng 2014). Given these findings, the DMN is the core of moral self, and the region of interest in virtue ethics and character psychology. We will be able to quantify the degree of the development of moral virtue at the neural level, and to approach the inner psychological processes of virtue and character, which has not been completely investigated, by investigating the strength and robustness of the functional connectivity between these DMN regions and other regions associated with individual moral functions, such as moral compassion and moral indignation.

We can examine the strength of the neural connectivity between brain regions associated with self-related processes and moral functions. The neural connectivity is 
calculated from the series of functional brain images that are acquired while participants are watching visual stimuli that induce moral emotional responses closely associated with moral virtue, or solving moral dilemmas. In addition to the brain connectivity under the task conditions, the connectivity measured during resting state is also informative as shown in previous DMN studies (e.g., Buckner et al. 2008). Finally, because it is usually expected that moral exemplars are successfully integrate moral virtue into their selfhood, their functional connectivity between brain regions dealing with moral and self-related functions would significantly differ from that among ordinary people. This approach can also contribute to the development of a more effective moral educational program by evaluating the effectiveness of the newly invented program. The quality of the program can be evaluated by measuring whether the program induces significant change in the functional connectivity specified by the functional neuroimaging project comparing ordinary people and moral exemplars.

Structural neuroimaging Structural neuroimaging studies have shown that various trainings including both physical and cognitive skill trainings induced significant changes in brains at the structural level (e.g., Scholz et al. 2009; Takeuchi et al. 2010). For instance, long-term trained players of the game of "Baduk (Go)," an Asian board game, showed a significantly different brain anatomy in the frontal, cinglulum, and striato-thalamic areas dealing with attentional control, working memory, executive regulation, and problem-solving, compared with non-experts (Lee et al. 2010). Thus, given this fact, we can expect that moral exemplars that have successfully habituated and internalized moral virtue would show significantly different structural characteristics in brain regions associated with moral and self-related functions compared with ordinary people.

Therefore, we can utilize the grey matter thickness measurement. It measures the thickness of grey matters in the region of interest using high-resolution structural brain images, and enables researchers to investigate developmental or pathological changes from the quantified thickness (Fischl and Dale 2000). For instance, O'Donnell et al. (2005) examined the developmental changes in the frontopolar area, which is associated with cognitive function, from childhood to adolescence using this method. Given the findings of previous studies using this method, the structural characteristics of grey matters were continuously affected by both internal (e.g., aging), and external (e.g., environment and training) factors (Lazar et al. 2005; O’Donnell et al. 2005). In addition, the diffusion-tensor imaging (DTI) can also be used to examine changes in brain regions. This method quantifies diffusion anisotropy effects in white matters, and investigates the microstructure of the human brain (Assaf and Pasternak 2008). The DTI method has also been applied to investigate the influences of both internal and external factors on the brain structure (e.g., Lee et al. 2010; Molinuevo et al. 2012; Scholz et al. 2009; Takeuchi et al. 2010).

Particularly, the structural changes in brain regions associated with moral function and the DMN to examine character development at the level of brain structure are important. In addition, researchers will be able to discover other brain regions that would be related to moral virtue, which have not been yet reported by previous studies, through the comparison in the brain anatomy between exemplars and ordinary people. In fact, structural changes were usually observed in a brain region that is directly associated with a function of interest in the previous studies of the brain structure (e.g., 
Lazar et al. 2005; Lee et al. 2010), so brain regions associated with moral virtue would show significantly different brain structures between moral exemplars and ordinary people. Again, we can expect that the habituation and internalization of moral virtue, which are the most important characteristics of moral exemplars, would be reflected in the structural feature of the regions. Furthermore, we will be able to apply the structural neuroimaging methods to evaluate the longitudinal effect of a newly invented moral educational program. The educational effect at the neural level can be measured by focusing on the degree of the structural change in regions selected by the exemplarbased experiment that is potentially induced by the program.

\section{Limitations and future directions}

However, we have to be aware of several limitations of the methods. First, we have to take into account that the majority of previous neuroimaging studies examining human morality have utilized hypothetical moral dilemmas instead of real problems (Christensen and Gomila 2012). If we do not seriously consider how to employ realistic dilemmas that can be implemented in neuroimaging settings, we cannot properly investigate the neural correlates of moral virtue and character because the development of moral virtue and character can only be completely evaluated if we investigate all of moral reasoning, moral affection, moral motivation, and moral behaviour (Curren and Kotzee 2014; Fowers 2014). Particularly, the core concept of virtue ethics, phronesis, cannot be properly understood by considering only cognitive aspect of human morality; the exercise of phronesis is inevitably associated with emotion, motivation and behaviour on top of moral reasoning (Stovall 2011; Hursthouse 2012; Kristjánsson 2014). Thus, we should develop a measurement of moral virtue and character that employs realistic situations inducing activation of all aspects of human moral functioning on top of moral reasoning, which has been mainly examined by previous neuroimaging studies using hypothetical dilemmas. Unfortunately, due to the restricted circumstance in MR scanners, the potential measurement would be inevitably text- and/or picturebased similar to previous moral dilemma tasks. Thus, recently developed text-based measurements based on virtue ethics, such as a prototype of gratitude measurement (Morgan et al. 2014), measurement for virtuous law practice (Arthur et al. 2014) and measurement for virtuous medical practice (Arthur et al. 2015), would be most promising candidates that can be utilized in neuroimaging studies. These measurements can also be applied to measure the longitudinal effect of a newly developed virtue ethics-based moral educational program at the neural level.

Second, because neuroscientific studies of human morality have employed diverse experimental paradigms and tasks, they would not produce totally comparable and coherent results; it would significantly hinder the interpretation of the results. In fact, there have been concerns regarding the possibility of statistical idiosyncrasies that would be produced by the differences in methods while interpreting a set of results of multiple neuroimaging experiments (Wager et al. 2004). Thus, we should carefully consider how to address the possible idiosyncrasies, which would be problematic during the interpretation of multiple individual neuroimaging experiments, and how to properly find out the psychological and educational implications from them. One possible way is to utilize a meta-analysis of multiple neuroimaging studies; for 
instance, the Activation Estimated Likelihood (ALE) method implemented in GingerALE (Laird et al. 2005; Eickhoff et al. 2009) is a feasible meta-analysis method easily applied to analysis of neuroimaging studies in socio-moral neuroscience (Bzdok et al. 2012; Sevinc and Spreng 2014). Although the experiments included in the metaanalysis model would not be completely comparable or coherent with each other, the process of the meta-analysis is effective to reduce the statistical idiosyncrasies possibly embedded in individual experiments and to produce statistically reliable and valid outcomes (e.g., common activation foci, common neural correlates of a function of interest) (Wager et al. 2004; Etkin and Wager 2007; Costafreda 2009). Of course, the meta-analysis is also the most feasible method to increase the statistical power, which is likely to be week in each individual neuroimaging study due to its small sample size (Cacioppo et al. 2013). Scholars who are interested in neuroimaging studies of moral virtue and character can utilize this analysis method once multiple neuroimaging experiments, which might seem to be primarily incomparable, are conducted. They will be able to get statistically reliable, valid and powerful results by meta-analysing multiple experiments, and finally, to approach the neural-level mechanism of moral virtue and character. This kind of meta-analysis can also be applied to compare the effect of diverse moral educational approaches once neuroimaging studies examining the longitudinal effect of educational methods are performed and the findings are accumulated in a database.

\section{Concluding remarks}

The present essay reviewed the relationship between virtue ethics and contemporary neuroscience and how methods in neuroscience can contribute to the studies in moral philosophy, moral psychology, and moral education. First, the present essay discussed how and why virtue ethics and its psychological model are more coherent with contemporary neuroscience than are other ethical theories by considering the philosophical account of moral motivation and developmental model. Second, we sought how to apply neuroscientific methods, particularly functional and structural neuroimaging methods, to studies in moral philosophy, psychology and education based on virtue ethics while discussing their limitations and how to deal with the limitations. Given these discussions, the present essay concludes that virtue ethics and its psychological and educational models will be able to be well supported by experiments on the neural mechanism of morality and neuroscientific methods.

Of course, although scientific findings seem to support Aristotelian moral philosophy and psychology, we must not attempt merely to reduce the philosophical and developmental theories into activity of biological substances, or incautiously equate philosophy, psychology, and natural sciences. Then, what would be appropriate ways to address this issue? First, Aristotelian moral philosophy can provide ideas to establish hypotheses for neuroscientific investigations on morality, while neurosciences can support empirically the philosophical and developmental assumptions of Aristotelian ethics (Han 2014). Second, moral philosophically justified and psychologically effective moral educational interventions can be developed through the cooperation between Aristotelian moral philosophy, moral psychology, and neurosciences (e.g., neuroimaging experiments examining the effects of virtue ethics-based moral education) (Jeong and Han 2013; Han 2014). Through these methods, moral philosophy, psychology and 
education based on Aristotelian ethics and neurosciences dealing with morality will be able to benefit each other synergistically.

Acknowledgments The initial version of this essay was presented at The Second and Third Annual Conference of the Jubilee Centre for Character and Virtues, Oxford, UK. I would like to thank William Damon, Anne Colby, William B. Hurlbut, Heather Malin, Indrawati Liauw, Gary H. Glover, Yen-Hsin Chen and The Jubilee Centre for Character and Virtues Conference delegates for their comments and supports.

\section{References}

Adair, John G. 1984. The Hawthorne effect: a reconsideration of the methodological artifact. Journal of Applied Psychology 69: 334-345. doi:10.1037/0021-9010.69.2.334.

Alexander, Larry, and Michael Moore. 2012. Deontological Ethics. In Stanford encyclopedia of philosophy, ed. Edward E. Zalta.

Althof, Wolfgang, and Marvin W. Berkowitz. 2006. Moral education and character education: their relationship and roles in citizenship education. Journal of Moral Education 35: 495-518. doi: 10.1080/03057240601012204. Routledge.

Anscome, G.E.M. 1958. Modern moral philosophy. Philosophy 33: 1-19.

Aristotle. 2000. Nicomachean ethics. New York: Cambridge University Press.

Arthur, James. 2003. Education with character: the moral economy of schooling. London: Routledge Falmer.

Arthur, James, Kristjan Kristjansson, Hywel Thomas, Michael Holdsworth, Luca Badini Confalonieri, and Tian Qiu. 2014. Virtuous character for the practice of law: research report. Birmingham, UK.

Arthur, James, Kristjan Kristjansson, Hywel Thomas, B. Kotzee, Agnieszka Ignatowicz, and Tian Qiu. 2015. Virtuous Medical Practice: Research Report. Birmingham, UK.

Assaf, Y., and O. Pasternak. 2008. Diffusion tensor imaging (DTI)-based white matter mapping in brain research: a review. Journal of Molecular Neuroscience 34: 51-61. doi:10.1007/s12031-007-0029-0.

Bandura, A. 1990. Selective activation and disengagement of moral control. Journal of Social Issues 46: 27-46.

Bandura, A. 1999. Moral disengagement in the perpetration of inhumanities. Personality and Social Psychology Review 3: 193-209. doi:10.1207/s15327957pspr0303_3.

Barker, F.G. 1995. Phineas among the phrenologists: the American crowbar case and nineteenth-century theories of cerebral localization. Journal of Neurosurgery 82: 672-682. doi:10.3171/jns.1995.82.4.0672.

Barnett, Clive, Philip Cafaro, and Terry Newholm. 2005. Philosophy and ethical consumption. In The ethical consumer, ed. Rob Harrison, Terry Newholm, and Deirdre Shaw, 11-24. London: Sage.

Berkowitz, Marvin W. 2002. The science of character education. In Bringing in a new era in character education, ed. William Damon, 43-63. Stanford: Hoover Press.

Bjorklund, F., G. Bjornsson, J. Eriksson, R. Francen Olinder, and C. Strandberg. 2012. Recent work on motivational internalism. Analysis 72: 124-137. doi:10.1093/analys/anr118.

Blair, R.J.R. 2007. The amygdala and ventromedial prefrontal cortex in morality and psychopathy. Trends in Cognitive Sciences 11: 387-92. doi:10.1016/j.tics.2007.07.003.

Blasi, A. 2005. Moral character: a psychological approach. In Character psychology and character education, ed. D.K. Lapsley and F.C. Power, 67-100. Notre Dame: University of Notre Dame Press.

Bloom, Paul. 2012. Moral nativism and moral psychology. In The social psychology of morality: exploring the causes of good and evil, ed. Mario Mikulincer and Phillip R. Shaver, 71-89. Washington, DC: American Psychological Association.

Blum, Lawrence A. 1988. Gilligan and Kohlberg: implications for moral theory. Ethics 98: 472-491. doi:10.1086/292966.

Borg, Jana Schaich, Catherine Hynes, John Van Horn, Scott Grafton, and Walter Sinnott-Armstrong. 2006. Consequences, action, and intention as factors in moral judgments: an FMRI investigation. Journal of Cognitive Neuroscience 18: 803-817. doi:10.1162/jocn.2006.18.5.803.

Brink, David O. 1997. Moral motivation. Ethics 108: 4-32.

Buckner, Randy L., Jessica R. Andrews-Hanna, and Daniel L. Schacter. 2008. The brain's default network: anatomy, function, and relevance to disease. Annals of the New York Academy of Sciences 1124: 1-38. doi:10.1196/annals.1440.011. Wiley Online Library. 
Bzdok, Danilo, Leonhard Schilbach, Kai Vogeley, Karla Schneider, Angela R. Laird, Robert Langner, et al. 2012. Parsing the neural correlates of moral cognition: ALE meta-analysis on morality, theory of mind, and empathy. Brain Structure and Function 217: 783-796. doi:10.1007/s00429-012-0380-y.

Cacioppo, Stephanie, Chris Frum, Erik Asp, Robin M. Weiss, James W. Lewis, and John T. Cacioppo. 2013. A quantitative meta-analysis of functional imaging studies of social rejection. Scientific Reports 3: 2027. doi:10.1038/srep02027.

Carr, David. 2008. Character education as the cultivation of virtue. In Handbook of moral and character education, ed. Larry P. Nucci and Darcia Narvaez, 99-116. New York: Routledge.

Casey, B.J., Rebecca M. Jones, and Todd A. Hare. 2008. The adolescent brain. Annals of the New York Academy of Sciences 1124: 111-126. doi:10.1196/annals.1440.010.

Christensen, J.F., and A. Gomila. 2012. Moral dilemmas in cognitive neuroscience of moral decision-making: a principled review. Neuroscience \& Biobehavioral Reviews 36: 1249-1264. doi:10.1016/j.neubiorev.2012.02.008.

Colby, Anne, and William Damon. 1992. Some do care : contemporary lives of moral commitment. New York: Free Press.

Costafreda, Sergi G. 2009. Pooling FMRI data: meta-analysis, mega-analysis and multi-center studies. Frontiers in Neuroinformatics 3: 33. doi:10.3389/neuro.11.033.2009.

Curren, R., and B. Kotzee. 2014. Can virtue be measured? Theory and Research in Education 12: $266-282$. doi: $10.1177 / 1477878514545205$

Curzer, Howard J. 2012. Aristotle and the virtues. Oxford: Oxford University Press.

Damasio, Antonio R. 1994. Descartes' error: emotion, reason, and the human brain. New York: Harper Perennial.

De Colle, Simone, and Patricia H. Werhane. 2008. Moral motivation across ethical theories: what can we learn for designing corporate ethics programs? Journal of Business Ethics 81: 751-764. doi:10.1007/s10551-007-9545-7.

de Wit, S., P. Watson, H.A. Harsay, M.X. Cohen, I. van de Vijver, and K.R. Ridderinkhof. 2012. Corticostriatal connectivity underlies individual differences in the balance between habitual and goaldirected action control. Journal of Neuroscience. doi:10.1523/JNEUROSCI.1088-12.2012.

Decety, Jean, and Lauren H. Howard. 2013. The role of affect in the neurodevelopment of morality. Child Development Perspectives 7: 49-54. doi:10.1111/cdep.12020.

Decety, Jean, Kalina J. Michalska, and Katherine D. Kinzler. 2012. The contribution of emotion and cognition to moral sensitivity: a neurodevelopmental study. Cerebral Cortex 22: 209-220. doi:10.1093/cercor/bhr111.

Eickhoff, Simon B., Angela R. Laird, Christian Grefkes, Ling E. Wang, Karl Zilles, and Peter T. Fox. 2009. Coordinate-based activation likelihood estimation meta-analysis of neuroimaging data: a random-effects approach based on empirical estimates of spatial uncertainty. Human Brain Mapping 30: 2907-2926.

Englander, Zoë A., Jonathan Haidt, and James P. Morris. 2012. Neural basis of moral elevation demonstrated through inter-subject synchronization of cortical activity during free-viewing. Plos One 7, e39384. doi:10.1371/journal.pone.0039384. Public Library of Science.

Etkin, Amit, and Tor D. Wager. 2007. Functional neuroimaging of anxiety: a meta-analysis of emotional processing in PTSD, social anxiety disorder, and specific phobia. The American Journal of Psychiatry 164: 1476-1488. doi:10.1176/appi.ajp.2007.07030504.

Fischer, John Martin, and Mark Ravizza. 2000. Responsibility and control: a theory of moral responsibility. New York: Cambridge University Press.

Fischl, Bruce, and Anders M. Dale. 2000. Measuring the thickness of the human cerebral cortex from magnetic resonance images. Proceedings of the National Academy of Sciences of the United States of America 97: 11050-11055. doi:10.1073/pnas.200033797.

Fowers, B.J. 2014. Toward programmatic research on virtue assessment: challenges and prospects. Theory and Research in Education. doi:10.1177/1477878514546064.

Galvan, Adriana, Todd A. Hare, Cindy E. Parra, Penn Jackie, Voss Henning, Glover Gary, et al. 2006. Earlier development of the accumbens relative to orbitofrontal cortex might underlie risk-taking behavior in adolescents. The Journal of Neuroscience: the Official Journal of the Society for Neuroscience 26: 688592. doi:10.1523/JNEUROSCI.1062-06.2006.

Greene, J.D. 2007. The secret joke of Kant's soul. In Moral psychology, vol. 3: the neuroscience of morality: emotion, disease, and development, ed. W. Sinnott-Armstrong, 35-80. Cambridge: MIT Press.

Greene, J.D., R.B. Sommerville, L.E. Nystrom, J.M. Darley, and J.D. Cohen. 2001. An fMRI investigation of emotional engagement in moral judgment. Science 293: 2105-2108. doi:10.1126/science.1062872.

Greene, J.D., L.E. Nystrom, A.D. Engell, J.M. Darley, and J.D. Cohen. 2004. The neural bases of cognitive conflict and control in moral judgment. Neuron 44: 389-400. doi:10.1016/j.neuron.2004.09.027. 
Greene, J.D., Lisa E. Stewart, Kelly Lowenberg, Leigh E. Nystrom, and Jonathan D. Cohen. 2009. Pushing moral buttons: the interaction between personal force and intention in moral judgment. Cognition 111: 364-371. doi:10.1016/j.cognition.2009.02.001.

Hamlin, J. Kiley, Karen Wynn, and Paul Bloom. 2007. Social evaluation by preverbal infants. Nature 450: 557-9. doi:10.1038/nature06288.

Hamlin, J. Kiley, Karen Wynn, and Paul Bloom. 2010. Three-month-olds show a negativity bias in their social evaluations. Developmental Science 13: 923-9. doi:10.1111/j.1467-7687.2010.00951.x.

Han, Hyemin. 2014. Analyzing theoretical frameworks of moral education through Lakatos's philosophy of science. Journal of Moral Education 43: 32-53. doi:10.1080/03057240.2014.893422.

Han, Hyemin. 2015. Virtue ethics, positive psychology, and a new model of science and engineering ethics education. Science and Engineering Ethics 21: 441-460. doi:10.1007/s11948-014-9539-7.

Han, Hyemin, Gary H. Glover, and Changwoo Jeong. 2014. Cultural influences on the neural correlate of moral decision making processes. Behavioural Brain Research 259: 215-28. doi:10.1016/j.bbr.2013.11.012.

Han, Hyemin, Jingyuan Chen, Changwoo Jeong, and Gary H. Glover. 2016. Influence of the cortical midline structures on moral emotion and motivation in moral decision-making. Behavioural Brain Research 302: 237-251. doi:10.1016/j.bbr.2016.01.001.

Hare, Todd A., Nim Tottenham, Adriana Galvan, Henning U. Voss, Gary H. Glover, and B.J. Casey. 2008. Biological substrates of emotional reactivity and regulation in adolescence during an emotional go-nogo task. Biological Psychiatry 63: 927-34. doi:10.1016/j.biopsych.2008.03.015.

Harenski, Carla L., Keith A. Harenski, Matthew S. Shane, and Kent A. Kiehl. 2012. Neural development of mentalizing in moral judgment from adolescence to adulthood. Developmental Cognitive Neuroscience 2: 162-173. doi:10.1016/j.den.2011.09.002.

Hartman, Edwin M. 2006. Can we teach character? An Aristotelian answer. Academy of Management Learning and Education 5: 68-81. doi:10.5465/AMLE.2006.20388386.

Hursthouse, Rosalind. 2012. Virtue Ethics. In Stanford Encyclopedia of Philosophy, ed. Edward N. Zalta.

Immordino-Yang, Mary Helen, Andrea McColl, Hanna Damasio, and Antonio Damasio. 2009. Neural correlates of admiration and compassion. Proceedings of the National Academy of Sciences 106: 80218026. doi:10.1073/pnas.0810363106.

Immordino-Yang, Mary Helen, Joanna A. Christodoulou, and Singh Vanessa. 2012. Rest is not idleness implications of the Brain's default mode for human development and education. Perspectives on Psychological Science 7: 352-364. doi:10.1177/1745691612447308. Sage Publications.

Ito, Tiffany A., and John T. Cacioppo. 2007. Attitudes as mental and neural states of readiness: using physiological measures to study implicit attitudes. In Implicit measures of attitudes, ed. B. Wittenbrink and N. Schwarz, 125-158. New York: Guilford Press.

Jacobs, Jon. 2014. Naturalism. The Internet encyclopedia of philosophy. Retrieved February 10, 2016, from the Internet Encyclopedia of Philosophy. http://www.iep.utm.edu/naturali/.

Jeong, Changwoo, and Hyemin Han. 2013. Exploring the relationship between virtue ethics and moral identity. Ethics \& Behavior 23: 44-56. Taylor \& Francis.

Jeurissen, Danique, Alexander T. Sack, Alard Roebroeck, Brian E. Russ, and Alvaro Pascual-Leone. 2014. TMS affects moral judgment, showing the role of DLPFC and TPJ in cognitive and emotional processing. Frontiers in Neuroscience. doi:10.3389/fnins.2014.00018.

Kihlstrom, John F. 2010. Social neuroscience: the footprints of Phineas gage. Social Cognition 28: 757-783. doi:10.1521/soco.2010.28.6.757.

Kohlberg, Lawrence. 1981. The philosophy of moral development: moral stages and the idea of justice. San Francisco: Harper \& Row.

Kohlberg, Lawrence. 1984. The psychology of moral development: the nature and validity of moral stages. San Francisco: Harper \& Row.

Kraut, Richard. 2014. Aristotle's Ethics. In Stanford Encyclopedia of Philosophy, ed. Edward N. Zalta. Retrieved February 10, 2016, from Stanford University. http://plato.stanford.edu/entries/aristotle-ethics/.

Kristjánsson, Kristján. 2000. Virtue ethics and emotional conflict. American Philosophical Quarterly 37: 193-207.

Kristjánsson, Kristján. 2007a. Aristotle, emotions and education. Aldershot: Ashgate Publishing.

Kristjánsson, Kristján. 2007b. Measuring self-respect. Journal for the Theory of Social Behaviour 37: 225242. doi:10.1111/j.1468-5914.2007.00339.x. Wiley Online Library.

Kristjánsson, Kristján. 2012. Aristotelian motivational externalism. Philosophical Studies 164: 419-442. doi: 10.1007/s11098-012-9863-1.

Kristjánsson, Kristján. 2013. Virtues and vices in positive psychology: a philosophical critique. New York: Cambridge University Press. 
Kristjánsson, Kristján. 2014. Phronesis and moral education: treading beyond the truisms. Theory and Research in Education. doi:10.1177/1477878514530244.

Laird, A.R., J.L. Lancaster, and P.T. Fox. 2005. BrainMap: the social evolution of a human brain mapping database. Neuroinformatics 3: 65-78.

Lazar, Sara W., Catherine E. Kerr, Rachel H. Wasserman, Jeremy R. Gray, Douglas N. Greve, Michael T. Treadway, et al. 2005. Meditation experience is associated with increased cortical thickness. Neuroreport 16: 1893-1897. doi:10.1097/01.wnr.0000186598.66243.19.

LeDoux, Joseph E. 2002. Synaptic self: how our brains become who we are. New York: Viking.

Lee, C., and M.J. Taylor. 2013. Moral education trends over 40 years: a content analysis of the journal of moral education (1971-2011). Journal of Moral Education 42: 399-429. doi:10.1080/03057240.2013.832666.

Lee, Boreom, Ji-Young Park, Wi Hoon Jung, Hee Sun Kim, S. Oh Jungsu, Chi-Hoon Choi, et al. 2010. White matter neuroplastic changes in long-term trained players of the game of "Baduk" (GO): a voxel-based diffusion-tensor imaging study. NeuroImage 52: 9-19. doi:10.1016/j.neuroimage.2010.04.014.

Lickona, Thomas. 1996. Eleven principles of effective character education. Journal of Moral Education. doi: 10.1080/0305724960250110.

Lingawi, N.W., and B.W. Balleine. 2012. Amygdala central nucleus interacts with dorsolateral striatum to regulate the acquisition of habits. Journal of Neuroscience. doi:10.1523/JNEUROSCI.4806-11.2012.

Lou, Hans C., Bruce Luber, Arielle Stanford, and Sarah H. Lisanby. 2010. Self-specific processing in the default network: a single-pulse TMS study. Experimental Brain Research 207: 27-38. doi: 10.1007/s00221-012-3249-7.

Mackey, Allyson P., Kirstie J. Whitaker, and Silvia A. Bunge. 2012. Experience-dependent plasticity in white matter microstructure: reasoning training alters structural connectivity. Frontiers in Neuroanatomy 6: 32. doi:10.3389/fnana.2012.00032.

Mele, Alfred R. 1989. Motivational internalism: the powers and limits of practical reasoning. Philosophia 19: 417-436. doi:10.1007/BF02380275.

Molewijk, Bert, Dick Kleinlugtenbelt, and Guy Widdershoven. 2011. The role of emotions in moral case deliberation: theory, practice, and methodology. Bioethics 25: 383-393. doi:10.1111/j.1467-8519.2011.01914.x.

Molinuevo, José Luis, Núria Bargalló, Carme Junqué, Cristina Solé-Padullés, David Bartrés-Faz, Eider M. Arenaza-Urquijo, et al. 2012. Multiple DTI index analysis in normal aging, amnestic MCI and AD. Relationship with neuropsychological performance. Neurobiology of Aging. doi:10.1016/j. neurobiolaging.2010.02.004.

Moll, Jorge, and Ricardo de Oliveira-Souza. 2007. Moral judgments, emotions and the utilitarian brain. Trends in Cognitive Sciences 11: 319-21. doi:10.1016/j.tics.2007.06.001.

Moll, Jorge, Ricardo De Oliveira-Souza, Griselda J. Garrido, Ivanei E. Bramati, Egas M.A. Caparelli-Daquer, Mirella L.M.F. Paiva, et al. 2007. The self as a moral agent: linking the neural bases of social agency and moral sensitivity. Social Neuroscience 2: 336-352. doi:10.1080/17470910701392024.

Morgan, Blaire, Liz Gulliford, and Kristján Kristjánsson. 2014. Gratitude in the UK: a new prototype analysis and a cross-cultural comparison. The Journal of Positive Psychology 9: 281294. doi:10.1080/17439760.2014.898321.

Narvaez, Darcia, and Daniel K. Lapsley. 2005. The psychological foundations of everyday morality and moral expertise. In Character psychology and character education, ed. Daniel K. Lapsley and F. Clark Power, 140-165. Notre Dame: University of Notre Dame Press.

Narvaez, Darcia, and Jenny L. Vaydich. 2008. Moral development and behaviour under the spotlight of the neurobiological sciences. Journal of Moral Education 37: 289-312. doi:10.1080/03057240802227478.

Nunner-Winkler, Gertrud. 1997. The development of moral understanding and moral motivation. International Journal of Educational Research 27: 587-603. doi:10.1016/S0883-0355(97)00056-6.

O'Donnell, S., M.D. Noseworthy, B. Levine, and M. Dennis. 2005. Cortical thickness of the frontopolar area in typically developing children and adolescents. NeuroImage 24: 948-954. doi:10.1016/j.neuroimage.2004.10.014.

Olesen, P.J., H. Westerberg, and T. Klingberg. 2004. Increased prefrontal and parietal activity after training of working memory. Nature Neuroscience 7: 75-79. doi:10.1038/Nn1165.

Pellegrino, Edmund D. 1995. Toward a virtue-based normative ethics for the health professions. Kennedy Institute of Ethics Journal 5: 253-277. doi:10.1353/ken.0.0044.

Piaget, Jean. 1948. The moral judgment of the child. New York: Free Press.

Poldrack, Russell A. 2008. The role of fMRI in cognitive neuroscience: where do we stand? Current Opinion in Neurobiology. doi:10.1016/j.conb.2008.07.006.

Reniers, Renate L.E.P., Rhiannon Corcoran, Birgit A. Völlm, Mashru Asha, Howard Richard, and Peter F. Liddle. 2012. Moral decision-making, ToM, empathy and the default mode network. Biological Psychology 90: 202-10. doi:10.1016/j.biopsycho.2012.03.009. 
Rosati, Connie S. 2006. Moral motivation. In Stanford encyclopedia of philosophy, ed. Edward N. Zalta.

Sanderse, Wouter. 2012. Character education: a Neo-Aristotelian approach to the philosophy, psychology and education of virtue. Delft: Eburon Academic Publishers.

Sanderse, Wouter. 2014. An Aristotelian model of moral development. Journal of Philosophy of Education. doi:10.1111/1467-9752.12109.

Saver, J.L., and A.R. Damasio. 1991. Preserved access and processing of social knowledge in a patient with acquired sociopathy due to ventromedial frontal damage. Neuropsychologia 29: 1241-1249. doi: 10.1016/0028-3932(91)90037-9.

Scholz, Jan, Miriam C. Klein, Timothy E.J. Behrens, and Johansen-Berg Heidi. 2009. Training induces changes in white-matter architecture. Nature Neuroscience 12: 1370-1371. doi:10.1038/nn.2412.

Sevinc, Gunes, and R. Nathan Spreng. 2014. Contextual and perceptual brain processes underlying moral cognition: a quantitative meta-analysis of moral reasoning and moral emotions. PLoS ONE 9, e87427. doi:10.1371/journal.pone.0087427.

Shafer-Landau, Russ. 2000. A defense of motivational externalism. Philosophical Studies 97: 267-291. doi: 10.1023/A:1018609130376.

Silverstein, Albert, and Isabel Trombetti. 2013. Aristotle's account of moral development. Journal of Theoretical and Philosophical Psychology 33: 233-252. doi:10.1037/a0031013.

Sinnott-Armstrong, Walter. 2011. Consequentialism. In Stanford Encyclopedia of Philosophy, ed. Edward E. Zalta.

Snow, Nancy E. 2008. Virtue and flourishing. Journal of Social Philosophy 39: 225-245. doi: 10.1111/j.1467-9833.2008.00425.x.

Stocker, Michael. 2003. The schizophrenia of modern ethical theories. In Roger crisp and michael slote, ed. Virtue Ethics, 66-78. Oxford: Oxford University Press.

Stovall, Preston. 2011. Professional virtue and professional self-awareness: a case study in engineering ethics. Science and Engineering Ethics 17: 109-132. doi:10.1007/s11948-009-9182-x.

Takeuchi, Hikaru, Atsushi Sekiguchi, Yasuyuki Taki, Satoru Yokoyama, Yukihito Yomogida, Nozomi Komuro, et al. 2010. Training of working memory impacts structural connectivity. The Journal of Neuroscience: the Official Journal of the Society for Neuroscience 30: 3297-3303. doi:10.1523/JNEUROSCI.4611-09.2010.

Tassy, Sébastien, Olivier Oullier, Yann Duclos, Olivier Coulon, Julien Mancini, Christine Deruelle, et al. 2012. Disrupting the right prefrontal cortex alters moral judgement. Social Cognitive and Affective Neuroscience 7: 282-288. doi:10.1093/scan/nsr008.

Tranel, Daniel. 2002. Emotion, decision making, and the ventromedial prefrontal cortex. In Principles of frontal lobe function, ed. D.T. Stuss and R.T. Knight, 338-353. Oxford: Oxford University Press.

Tricomi, Elizabeth, Bernard W. Balleine, and John P. O'Doherty. 2009. A specific role for posterior dorsolateral striatum in human habit learning. European Journal of Neuroscience 29: 2225-2232. doi: 10.1111/j.1460-9568.2009.06796.x.

Wager, Tor D., John Jonides, and Susan Reading. 2004. Neuroimaging studies of shifting attention: a metaanalysis. NeuroImage 22: 1679-1693. doi:10.1016/j.neuroimage.2004.03.052.

Walker, L.J. 2013. Moral motivation through the perspective of exemplarity. In Handbook of moral motivation: theories, models, applications, ed. K. Heinrichs, F. Oser, and T. Lovat, 197-214. Rotterdam: Sense Publishers.

Wall, John. 2003. Phronesis, poetics, and moral creativity. Ethical Theory and Moral Practice 6: 317-341. doi:10.1023/A:1026063925726.

Wilson, F.A.W., and E.T. Rolls. 2005. The primate amygdala and reinforcement: a dissociation between rulebased and associatively-mediated memory revealed in neuronal activity. Neuroscience 133: 1061-72. doi: 10.1016/j.neuroscience.2005.03.022.

Woodhead, Martin, and Dorothy Paulkner. 2000. Subjects, objects or participants? Dilemmas of psychological research with children. In Research with children: perspectives and practices, 2nd ed, ed. Pia Christensen and Allison James, 10-39. New York, NY: Routledge.

Wright, Samantha B., Bryan J. Matlen, Carol L. Baym, Ferrer Emilio, and Silvia A. Bunge. 2008. Neural correlates of fluid reasoning in children and adults. Frontiers in Human Neuroscience 1: 8. doi: 10.3389/neuro.09.008.2007.

Young, Liane, Joan Albert Camprodon, Marc Hauser, Alvaro Pascual-Leone, and Rebecca Saxe. 2010. Disruption of the right temporoparietal junction with transcranial magnetic stimulation reduces the role of beliefs in moral judgments. Proceedings of the National Academy of Sciences of the United States of America 107: 6753-6758. doi:10.1073/pnas.0914826107.

Zagzebski, Linda Trinkaus. 1996. Virtues of the mind: an inquiry into the nature of virtue and the ethical foundations of knowledge. Cambridge: Cambridge University Press.

Zhu, Y., L. Zhang, J. Fan, and S.H. Han. 2007. Neural basis of cultural influence on self-representation. NeuroImage 34: 1310-1316. doi:10.1016/j.neuroimage.2006.08.047. 